\title{
7. 渡邊忠夫，一桷八重子：芳香族第一級アミンの堂素簡易定量法
}

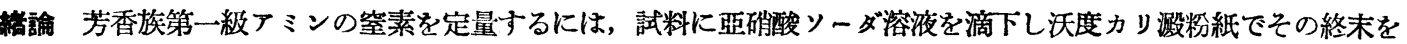
見る方法があるが，その終末點が明膫でないのみならず時間を要し，又色素類に就ては施行し得ない等の缺點がある.

適々著者等は芳香族第一級アミンと他のアミン類との分離定量の必要に迫られ, 以下記載の如くVan-Slyke氏法1) の改良を考案し，本法で諸隀の芳香族第一級へミン類を定量し，略了所期の目的を達し得た.Van-Slyke 氏のアミ，

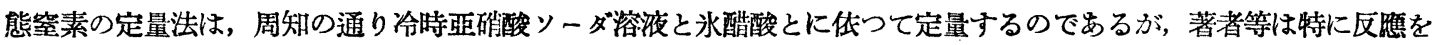

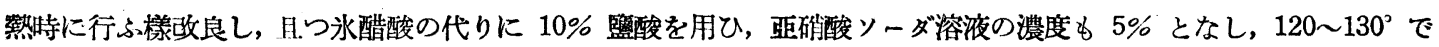

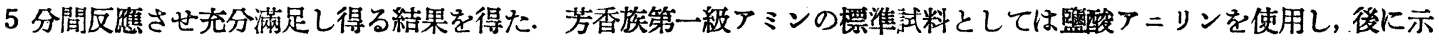
す如く定量條件を決定し，之に基いて更に Anthranilsäure, Toluidin, Sulfanilsäure, Nitrotoluidin, Anästhesin, $p$ Nitranilin, $\alpha$-Naphtylamin-HCl, $\beta$-Naphtylamin, Dibromanilin, Acetanilid, Benzidin, 4-Aminobenzolsulfonsäurediäthylamid, Sulfanilanilid, Sulfathiazol, 4-Aminobenzolsulfonsäure 3', 5'-Dibromanilid, Acrinol, Myo-Arsenobenzol に就てその窒素を定量した. 本法の倓點としては, Van-Slyke 氏法に基づく䉆試料を溶夜にしなくてはなら

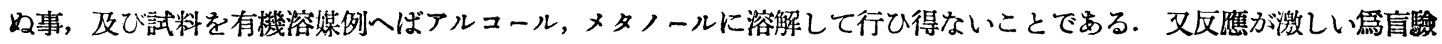
の值が稍々大である恨がある．作し芳香族第一級アミンのみならず, 脂肪族の檢體中舊來の Van-Slyke 氏法では室 素定量困難なもの，或は洋色物筫にありても本法により短時間內に正確な值の得られることが利點と考へられる.

\section{定量菑施法}

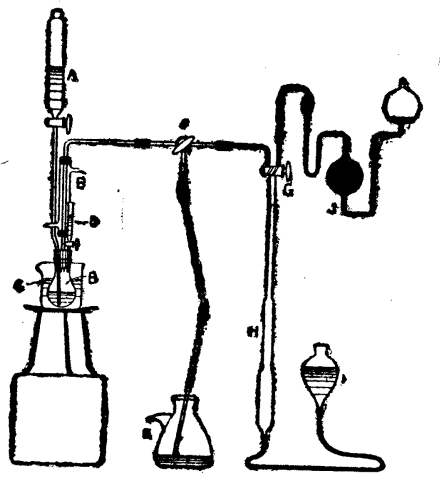

\section{I. 警 量}

A. 內容 $50 \mathrm{cc}$ の分液漏斗.

B. 內容約 $30 \mathrm{cc}$ の廣口丸底コルベンで $10 \mathrm{cc}$ の所に標線を附子。

C. 內容約 $300 \mathrm{cc}$ の硝子製の水浴或はグリセリン浴.

D. 檢體を容れる內容約 $2.5 \mathrm{cc}$ の小ビニレット.

E. 小型冷却器.

F. 三方活栓.

G. 二孔活栓.

H. 水を滿した內容 $45 \mathrm{cc}$ のアッォトメーター。

I. 內容約 $100 \mathrm{cc}$ で長い厚壁ゴム管を附し水を淽し $\mathrm{H}$ のてッォトメーターに 連結する水隻瓶.

J. アルカリ性過マンガン酸カリ溶液 $60 \mathrm{cc}$ を容れるヘンペルピペツト.

K. ガスの發生甚だしい爲吸引ナる吸引瓶.

II. 操作法 約 $\frac{\mathrm{mol}}{1500 \mathrm{n}}$ の檢體 ( $\mathrm{n}$ は檢體中の第一級アミンの室素の數を示す)を精科し, $50 \mathrm{cc} の$ 水に溶かしこの 2cc を使用す. 但し大部分の檢體は水に難溶であるから, 豫め少量の鳐酸或は水醋酸に溶解した後水で稀釋しなくて

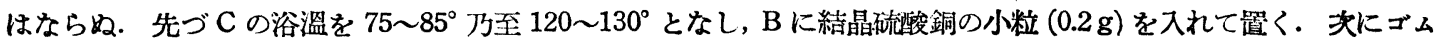

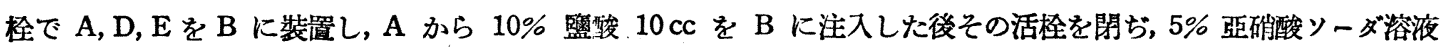
$40 \mathrm{cc}$ を A K入れ, 活栓 Fによつて B を吸引瓶 $\mathrm{K}$ と連絡させたる後 A の活栓を開いて亞硝酸ソーダ溶液を $\mathrm{B}$ に流 下させ發生する亞硒酸ガスで B 中の空氣を追ひ出す．この操作を約 10 回繰返した後，B 中の溶液を $10 \mathrm{cc}$ の標線 に一致させ， A の活栓を閉ち， F と G の活栓を聞き I なる水準瓶を下げて D (活栓から下の部分は潒め水を满して 置く) なる小ビニレットより檢體溶液を入れる. このビニレットを約 $1 \mathrm{cc}$ の水で 2 国洗浟後 B 中に落し, 發生するカ スを $\mathrm{H}$ なるアッオトメーターに導く，反隹 5 分の後 $A$ の活栓を開き $\mathrm{F}, \mathrm{G}$ を連絡して B 中の反隹液を $\mathrm{H}$ の稍上部 汽導き入れ，然る後活栓 $\mathrm{G}$ Jなるへンペルピペットに通じ，I を持上げガスをアルカリ性過マンガン酸カリ溶液上

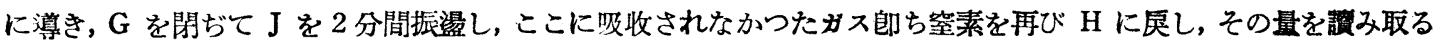
こと Van-Slyke 氏法と同樣に行ふ。.

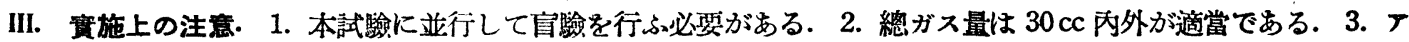

1) J. Biol. Chem. 9, 185 [1911]. Abderhalden: Hand. Biochem. Arbeit. Bd. V 2,998 [1912]. 
ルカリ性過マンガン酸カリ溶液は最初ガスの吸收が惡いので, 亞确酸ガス $60 \mathrm{cc}$ 位吸收させた後 10 回位試驗に供す る. 4. 排出したガスをアルカリ性過マンガン酸カリ溶液に吸收させるため振温子る時間は 2 分間が通當である. 5. 洷素の計算はアミノ態窒素定量の際の表2)に体つて行つた. 6. 反應中檢體により泡騰することがある, かかる場合 にはアミルアルコール少量を加へるがよい.

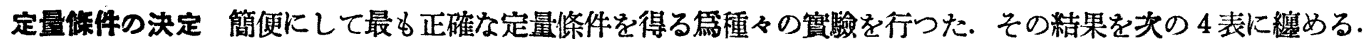
標淮試料 祭酸アニリン(䇪素理論量 $10.20 \%$ ).

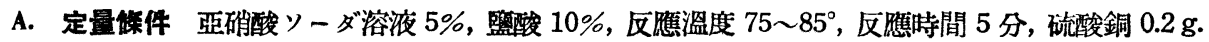

\begin{tabular}{|c|c|c|c|c|c|c|}
\hline 檢體量 mg & 總ガス量 cc & 溫度 $\mathrm{C}^{\circ}$ & 氣厴 $\mathrm{mm}$ & 窒素量 cc & 窒素 \% & 誤差 \% \\
\hline 4.090 & 30 & 21 & 764.4 & 0.79 & 10.99 & +0.19 \\
\hline ", & 30 & 20 & " & 0.79 & 11.05 & +0.25 \\
\hline , & 26 & 19 & 768.0 & 0.75 & 10.60 & -0.20 \\
\hline " & 31 & 18 & " & 0.73 & 10.37 & -0.43 \\
\hline
\end{tabular}

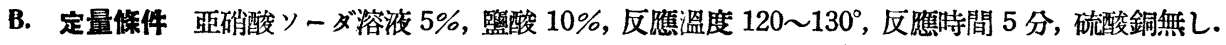

\begin{tabular}{|c|c|c|c|c|c|c|}
\hline 檢體聂 mg & 總ガス量 cc & 溫度 $\mathrm{C}^{\circ}$ & 氣嬮 mm & 窒素堅 cc & 窒素\% & 誤差 \% \\
\hline 4.224 & 33 & 28 & 756.0 & 0.84 & 10.80 & 0 \\
\hline ", & 36 & 28 & $"$ & 0.84 & 10.80 & 0 \\
\hline$"$ & 36 & 28 & $"$ & 0.83 & 10.67 & -0.13 \\
\hline , & 37 & 29 & $"$ & 0.84 & 10.74 & -0.06 \\
\hline " & 33 & 30 & " & 0.84 & 10.68 & --0.12 \\
\hline
\end{tabular}

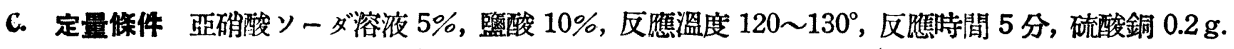

\begin{tabular}{|c|c|c|c|c|c|c|}
\hline 檢體量 mg & 總ガス量 c.c & 溫度 $C^{\prime}$ & 氣叞 m.m & 窒素量 c.c & 窒量 \% & 誤差 \% \\
\hline 4.244 & 29 & 27 & 759.0 & 0.84 & 10.85 & +0.05 \\
\hline$"$ & 36 & $"$ & $"$ & 0.84 & 10.85 & +0.05 \\
\hline " & 34 & $"$ & $"$ & 0.84 & 10.85 & +0.05 \\
\hline , & 29 & 28 & $"$ & 0.83 & 10.66 & -0.14 \\
\hline$"$ & 30 & $"$ & $"$ & 0.83 & 10.66 & -0.14 \\
\hline
\end{tabular}

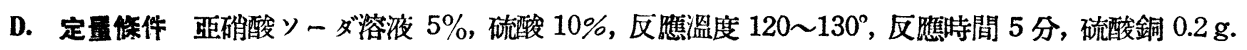

\begin{tabular}{|c|c|c|c|c|c|c|}
\hline 檢體量 mg & 總ガス量 cc & 温度 $\mathrm{C}^{\circ}$ & 氣熙 mm & 窒素量 cc & 䇪 荎\% & 誤差\% \\
\hline 4.244 & 28 & 29 & 764.5 & 0.84 & 10.82 & +0.02 \\
\hline$"$ & 28 & 28 & " & 0.84 & 10.88 & +0.08 \\
\hline$"$ & 30 & 27 & $"$ & 0.82 & 10.68 & -0.12 \\
\hline " & 26 & 27 & $"$ & 0.80 & 10.42 & -0.38 \\
\hline " & ?3 & 28 & ” & 0.84 & 10.88 & +0.08 \\
\hline
\end{tabular}

(1) 亞硝酸ソーダ溶液のミ度 從來の Van-Slyke 氏法では亞碓酸ソーダ溶液の濃度は $30 \%$ であるが, 著者等は加

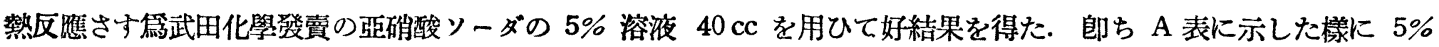

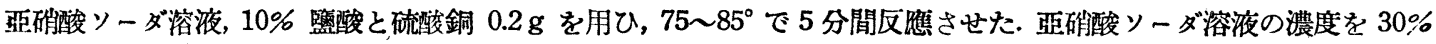
にしても之と全く同じ結果が得られた。郎ち亞确酸ソーダ溶液は $5 \%$ で充分である.

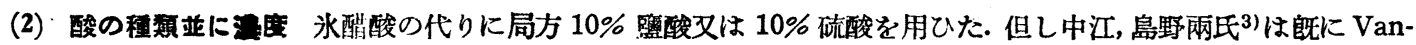

2) Paul Francis Sharp: J. Biol. Chem. 60, 77 [1924].

3) 中江, 島野: 釀造學 18, 423 [昭 15] 


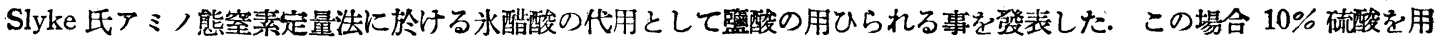
ひても同楾定量出來ることは D 表に示した通りである.

(3) 反磼溫度 標準訆料の監酸アニリンに就て常溫, $50 \sim 60^{\circ}, 75 \sim 85^{\circ}, 120 \sim 130^{\circ}$ と順次溫度を上げて行つたが，

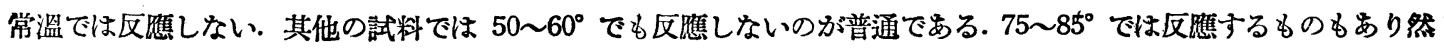

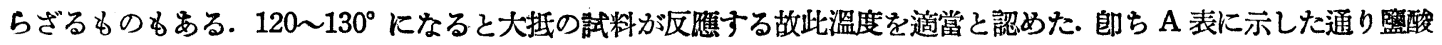

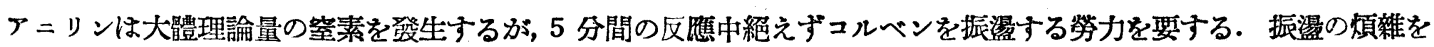

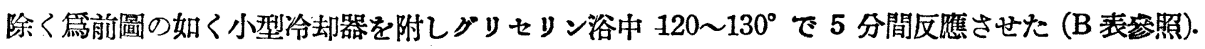

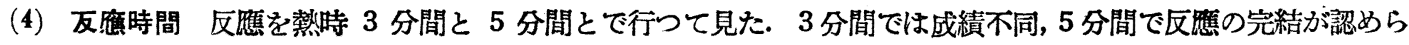
れた.

(5) 矿酸銅 多くの試料は硫酸銅を用ひなくとも反磼させ得るが $p$-Nitranilin, Acrinol 等では成績が低く出るの で, 一般的の定量としては C 表に示した樣に結晶硫酸銅 $0.2 \mathrm{~g}$ を使用するがよい.

（6） ガス吸收用アルカリ性溫マンガン酸カリ溶液 $2.5 \mathrm{~g}$ の苛性カリと $5 \mathrm{~g}$ の過マンガン酸カリとを水 $100 \mathrm{c.c}$ K 溶解する. ヘンベルビベットにはこの溶夜 $60 \mathrm{cc}$ を容れる. 此等の豫備試驗から C 表の如く, $5 \%$ 亞硝酸ソーダ溶

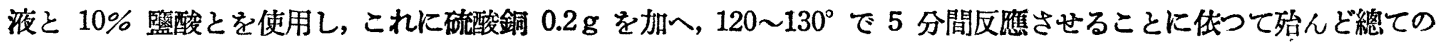
試料から理論量の䇪素を得たので, 之を以て芳香族第一級アミン跮素定量法の條件とした. 次に我々の得た賽驗例を 表示する.

\begin{tabular}{|c|c|c|c|c|c|c|c|}
\hline 物 質 名 & 檢體量 mg & 溫度 $\mathrm{C}^{\circ}$ & 氣筀 $\mathrm{mm}$ & 窒素 cc & 窒素 \% & 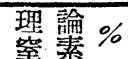 & 誤差 \% \\
\hline $\begin{array}{l}-\mathrm{NH}_{2}^{-} \\
\mathrm{COOH}\end{array}$ & $\begin{array}{c}4.112 \\
" \\
" \\
" \\
"\end{array}$ & $\begin{array}{c}22 \\
" \\
" \\
23\end{array}$ & $\begin{array}{c}768.2 \\
7 \\
766.6 \\
" \\
"\end{array}$ & $\begin{array}{l}0.72 \\
0.70 \\
0.73 \\
0.71 \\
0.73\end{array}$ & $\begin{array}{r}9.97 \\
9.70 \\
10.10 \\
9.82 \\
10.05\end{array}$ & 10.21 & $\begin{array}{l}-0.24 \\
-0.51 \\
-0.11 \\
-0.39 \\
-0.16\end{array}$ \\
\hline $\begin{array}{lll}\mathrm{NH}_{2} & 0.0995 \mathrm{~g} \\
\text { を水にて } \\
25 \mathrm{cc} \\
\text { な⿱ }\end{array}$ & $\begin{array}{c}3.980 \\
\quad \\
" \\
" \\
"\end{array}$ & $\begin{array}{l}21 \\
" \\
23 \\
" \\
"\end{array}$ & $\begin{array}{c}762.6 \\
" \\
" \\
" \\
"\end{array}$ & $\begin{array}{l}0.92 \\
0.93 \\
0.92 \\
0.94 \\
0.92\end{array}$ & $\begin{array}{l}13.14 \\
13.29 \\
13.01 \\
13.30 \\
13.01\end{array}$ & 13.08 & $\begin{array}{l}+0.06 \\
+0.21 \\
-0.07 \\
+0.22 \\
-0.07\end{array}$ \\
\hline$\left\{\begin{array}{l}0.1212 \mathrm{~g} \\
\text { を水にて } \\
50 \mathrm{cc} \text { と } \\
\mathrm{SO}_{3} \mathrm{H}\end{array}\right.$ & $\begin{array}{c}4.848 \\
" \\
" \\
"\end{array}$ & $\begin{array}{l}24 \\
" \\
" \\
"\end{array}$ & $\begin{array}{c}759.7 \\
" \\
" \\
"\end{array}$ & $\begin{array}{l}0.71 \\
0.72 \\
0.74 \\
0.72\end{array}$ & $\begin{array}{l}8.17 \\
8.28 \\
8.51 \\
8.28\end{array}$ & 8.09 & $\begin{array}{l}+0.08 \\
+0.19 \\
+0.42 \\
+0.19\end{array}$ \\
\hline 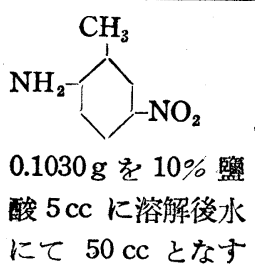 & $\begin{array}{c}4.128 \\
\quad " \\
" \\
" \\
"\end{array}$ & $\begin{array}{l}22 \\
23 \\
\Rightarrow " \\
24 \\
"\end{array}$ & $\begin{array}{c}766.2 \\
" \\
" \\
" \\
"\end{array}$ & $\begin{array}{l}0.68 \\
0.68 \\
0.70 \\
0.71 \\
0.71\end{array}$ & $\begin{array}{l}9.28 \\
9.33 \\
9.60 \\
9.69 \\
9.69\end{array}$ & 9.21 & $\begin{array}{l}+0.17 \\
+0.12 \\
+0.39 \\
+0.48 \\
+0.48\end{array}$ \\
\hline 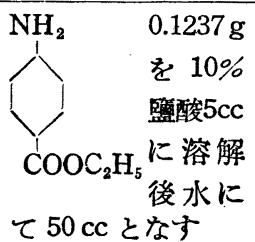 & $\begin{array}{c}4.948 \\
" \\
" \\
" \\
"\end{array}$ & $\begin{array}{l}23 \\
" \\
" \\
" \\
24\end{array}$ & $\begin{array}{c}769.7 \\
" \\
7 " \\
769.1 \\
"\end{array}$ & $\begin{array}{l}0.72 \\
0.77 \\
0.76 \\
0.75 \\
0.76\end{array}$ & $\begin{array}{l}8.27 \\
8.84 \\
8.73 \\
8.65 \\
8.67\end{array}$ & 8.49 & $\begin{array}{l}-0.22 \\
+0.35 \\
+0.24 \\
+0.11 \\
+0.18\end{array}$ \\
\hline
\end{tabular}




\begin{tabular}{|c|c|c|c|c|c|c|c|}
\hline 物 貿 名 & 检體量 mg & 溫度 $C_{3}$ & 氣㾔 mm & 窒素 cc & 窒素 〜 & 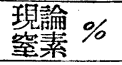 & 誤差 \% \\
\hline $\begin{array}{l}0.1015 \mathrm{~g} \text { を } 10 \% \text { 躳 } \\
0.0987 \mathrm{~g} \text { 酸 } 5 \mathrm{cc} \text { に溶解し水に } \\
\text { て } 50 \mathrm{cc} \text { となす } \\
\mathrm{NO}_{2}\end{array}$ & $\begin{array}{c}4.060 \\
\Rightarrow \\
3.948 \\
" \\
"\end{array}$ & $\begin{array}{l}21 \\
22 \\
20\end{array}$ & $\begin{array}{c}760.7 \\
7 " \\
769.4 \\
761.7\end{array}$ & $\begin{array}{l}0.73 \\
0.74 \\
0.70 \\
0.69 \\
0.71\end{array}$ & $\begin{array}{r}10.20 \\
10.34 \\
10.11 \\
9.97 \\
10.26\end{array}$ & 10.15 & $\begin{array}{l}+0.05 \\
+0.19 \\
-0.04 \\
-0.18 \\
+0.11 \\
\end{array}$ \\
\hline $\begin{array}{l}\mathrm{NH}_{2} \mathrm{HCl} \\
0.1249 \mathrm{~g} \text { を水にて } \\
50 \mathrm{cc} \text { となす }\end{array}$ & $\begin{array}{l}4.996 \\
" \\
" \\
"\end{array}$ & $\begin{array}{l}22 \\
21 \\
" \\
"\end{array}$ & $\begin{array}{l}767.4 \\
" \\
" \\
"\end{array}$ & $\begin{array}{l}0.68 \\
0.63 \\
0.67 \\
0.68\end{array}$ & $\begin{array}{l}7.82 \\
7.21 \\
7.67 \\
7.78\end{array}$ & 7.79 & $\begin{array}{l}+0.03 \\
-0.58 \\
-0.12 \\
-0.01\end{array}$ \\
\hline $\begin{array}{rl}-\mathrm{NH}_{2} & 0.1091 \mathrm{~g} \text { 水醋酸 } \\
& 5 \mathrm{cc} \text { に溶解挠水 } \\
& \text { Kて } 50 \mathrm{cc} \text { とな }\end{array}$ & $\begin{array}{l}4.364 \\
" \\
" \\
" \\
"\end{array}$ & $\begin{array}{l}21 \\
23 \\
24 \\
" \prime \\
25\end{array}$ & $\begin{array}{c}769.3 \\
773.6 \\
\quad " \\
" \\
"\end{array}$ & $\begin{array}{l}0.75 \\
0.75 \\
0.78 \\
0.77 \\
0.78\end{array}$ & $\begin{array}{r}9.85 \\
9.82 \\
10.16 \\
10.03 \\
10.03\end{array}$ & 9.79 & $\begin{array}{l}+0.66 \\
+0.03 \\
+0.37 \\
+0.24 \\
+0.31\end{array}$ \\
\hline $\begin{array}{l}\mathrm{Br} \\
\mathrm{Br} \\
\text { に溶解後永にて } 10 \% \text { 永監酸 } 10 \mathrm{cc}\end{array}$ & $\begin{array}{c}4.052 \\
", \\
" \\
" \\
"\end{array}$ & $\begin{array}{l}24 \\
23 \\
" \\
" \\
"\end{array}$ & $\begin{array}{c}764.4 \\
\Rightarrow " \\
770.3 \\
" \\
"\end{array}$ & $\begin{array}{l}0.37 \\
0.39 \\
0.37 \\
0.39 \\
0.37\end{array}$ & $\begin{array}{l}5.12 \\
5.43 \\
5.19 \\
5.47 \\
5.19\end{array}$ & 5.60 & $\begin{array}{l}-0.48 \\
-0.17 \\
-0.41 \\
-0.13 \\
-0.41\end{array}$ \\
\hline 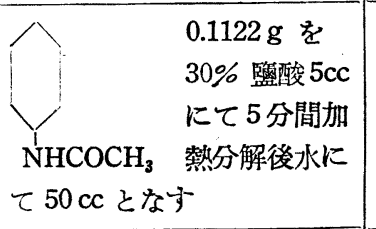 & $\begin{array}{c}4.488 \\
" \\
" \\
" \\
"\end{array}$ & $\begin{array}{c}27 \\
24 \\
" \\
"\end{array}$ & $\begin{array}{c}766.0 \\
" \\
763.7 \\
" \\
"\end{array}$ & $\begin{array}{l}c .81 \\
0.81 \\
0.81 \\
0.81 \\
0.81\end{array}$ & $\begin{array}{r}9.99 \\
9.99 \\
10.12 \\
10.12 \\
10.12\end{array}$ & 10.36 & $\begin{array}{l}-0.37 \\
-0.37 \\
-0.24 \\
-0.24 \\
-0.24\end{array}$ \\
\hline $\begin{array}{l}\mathrm{H}_{2} \mathrm{~N} \text { - } \\
0.0365 \mathrm{~g} \text { を水酷酸 } 5 \mathrm{cc} \mathrm{K} \\
\text { 溶解後水にて } 25 \mathrm{cc} \text { となす }\end{array}$ & $\begin{array}{l}2.920 \\
" \\
" \\
" \\
"\end{array}$ & $\begin{array}{l}28 \\
\Rightarrow \\
30 \\
" \\
"\end{array}$ & $\begin{array}{c}760.7 \\
\quad " \\
768.2 \\
" \\
"\end{array}$ & $\begin{array}{l}0.80 \\
0.80 \\
0.82 \\
0.82 \\
0.82\end{array}$ & $\begin{array}{l}14.98 \\
14.98 \\
15.32 \\
15.32 \\
15.32\end{array}$ & 15.21 & $\begin{array}{l}-0.23 \\
-0.23 \\
-0.11 \\
-0.11 \\
-0.11\end{array}$ \\
\hline 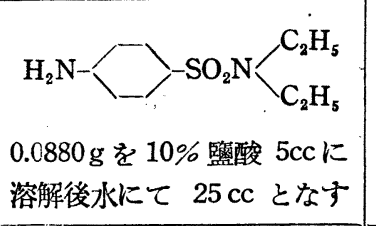 & $\begin{array}{c}6.840 \\
" \\
" \\
" \\
"\end{array}$ & $\begin{array}{l}26 \\
" \\
27 \\
27 \\
"\end{array}$ & $\begin{array}{c}769.7 \\
\quad " \\
" \\
" \\
"\end{array}$ & $\begin{array}{l}0.69 \\
0.71 \\
0.72 \\
0.74 \\
0.74\end{array}$ & $\begin{array}{l}5.64 \\
5.81 \\
5.89 \\
6.02 \\
6.02\end{array}$ & 6.14 & $\begin{array}{l}-0.50 \\
-0.33 \\
-0.25 \\
-0.12 \\
-0.12\end{array}$ \\
\hline 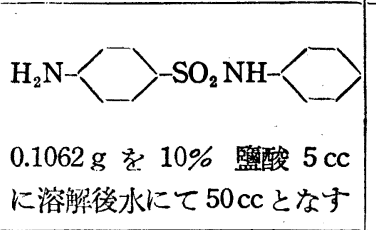 & $\begin{array}{c}4.248 \\
" \\
" \\
" \\
"\end{array}$ & $\begin{array}{l}25 \\
" \\
" \\
27\end{array}$ & $\begin{array}{c}774.2 \\
" \\
" \\
773.2\end{array}$ & $\begin{array}{l}0.41 \\
0.43 \\
0.44 \\
0.40 \\
0.43\end{array}$ & $\begin{array}{l}5.46 \\
5.72 \\
5.86 \\
5.32 \\
5.65\end{array}$ & 5.65 & $\begin{array}{l}-0.19 \\
+0.07 \\
+0.21 \\
-0.33 \\
\pm 0\end{array}$ \\
\hline 溶解後水にて & $\begin{array}{c}11.304 \\
\quad " \\
" \\
"\end{array}$ & $\begin{array}{l}20 \\
" \\
\ddot{21}\end{array}$ & $\begin{array}{l}772.8 \\
" \\
" \\
.\end{array}$ & $\begin{array}{l}1.09 \\
1.09 \\
1.11 \\
1.17\end{array}$ & $\begin{array}{l}5.58 \\
5.58 \\
5.69 \\
5.97\end{array}$ & 5.49 & $\begin{array}{l}+0.09 \\
+0.09 \\
+0.20 \\
+0.48\end{array}$ \\
\hline
\end{tabular}




\begin{tabular}{|c|c|c|c|c|c|c|c|}
\hline 物 賀 名 & 檢體量 mg & 溫度 $\mathrm{C}^{\circ}$ & 氣壓 mm & 荎素 cc & 窒素 \% & 理譣 \% & 誤差 \% \\
\hline $\begin{array}{l}\mathrm{H}_{2} \mathrm{~N}->-\mathrm{SO}_{2} \mathrm{NH} \backslash \\
0.1006 \mathrm{~g} \text { を水醋酸 } 10 \mathrm{cck} \\
\text { 溶解後水にて } 25 \mathrm{cc} \text { となす }\end{array}$ & $\begin{array}{c}8.048 \\
" \\
" \\
"\end{array}$ & $\begin{array}{l}27 \\
28 \\
" \\
"\end{array}$ & $\begin{array}{c}757.2 \\
" \\
" \\
"\end{array}$ & $\begin{array}{l}0.52 \\
0.51 \\
0.51 \\
0.52\end{array}$ & $\begin{array}{l}3.53 \\
3.45 \\
3.45 \\
3.51\end{array}$ & 3.45 & $\begin{array}{l}+0.08 \\
\pm 0 \\
\pm 0 \\
+0.06\end{array}$ \\
\hline 年 & $\begin{array}{l}6.516 \\
, " \\
" \\
" \\
"\end{array}$ & $\begin{array}{l}16 \\
" \\
" \\
"\end{array}$ & $\begin{array}{c}759.7 \\
" \\
" \\
764.5\end{array}$ & $\begin{array}{l}0.88 \\
0.87 \\
0.87 \\
0.84 \\
0.81\end{array}$ & $\begin{array}{l}7.83 \\
7.75 \\
7.75 \\
7.48 \\
7.21\end{array}$ & 7.75 & $\begin{array}{l}+0.08 \\
\pm \quad 0 \\
\pm 0 \\
-0.27 \\
-0.54\end{array}$ \\
\hline $\begin{array}{l}\mathrm{SO}_{3} \mathrm{Na} \text { OH } \mathrm{OH} \mathrm{SO}_{3} \mathrm{Na}_{2}^{-} \\
0.1463 \mathrm{~g} \text { を水にて } 25 \mathrm{cc} \text { とな } \\
\text { 空 }\end{array}$ & $\begin{array}{c}11.704 \\
" \\
" \\
" \\
"\end{array}$ & $\begin{array}{l}24 \\
25 \\
\ddot{2} \\
27 \\
26\end{array}$ & $\begin{array}{l}763.4 \\
" \\
" \\
" \\
"\end{array}$ & $\begin{array}{l}0.69 \\
0.69 \\
0.72 \\
0.70 \\
0.72\end{array}$ & $\begin{array}{l}3.30 \\
3.28 \\
3.43 \\
3.30 \\
3.41\end{array}$ & $\begin{array}{l}4.68 \% \text { な } \\
\text { るも } \\
\text { As= } \\
18.92 \% \\
\text { より計算 } \\
\text { すればは } \\
\text { 3.53\%と } \\
\text { なる }\end{array}$ & $\begin{array}{l}-0.23 \\
-0.25 \\
-0.10 \\
-0.23 \\
-0.10\end{array}$ \\
\hline
\end{tabular}

結論 本報告に依れば第一級アミンのみならず Acetanilid, Arsenobenzol の樣な第一級 ミミン誘道體も，之を監 酸で分解すれば第一級フミンとなる故間接的に定量し得る. $-\mathrm{NO}_{2},-\mathrm{SO}_{2} \mathrm{NH}_{2},-\mathrm{CONH}_{2}$ 等を有するもの及び Anisidin, Phenacetin 等は稍 3 定量困難である. Phenylendiamin は全く定量出來ないるのの一つである. 今後何研 究を重ねたいと思つて居る.

終に臨み本研究の機會を與へられたる武田二郎先生並に桑田博士に感謝の意を表す. 又實驗試料を與へられたる研 究部諸氏に梁謝子る.

株式會社武田長兵衞商店研究部（昭和 17 年 11 月 2 日受理）

\section{8. 瀧 浦 潔：丹參の成分研究 (第三報) タンシノン I の構造について}

さきに中尾氏11はタンシノン I の分子式を $\mathrm{C}_{18} \mathrm{H}_{12} \mathrm{O}_{3}$ と定め、その酸素の機能が - $\mathrm{CO} \cdot \mathrm{CO}$ - 及び $/ \mathrm{O} \backslash$ なること

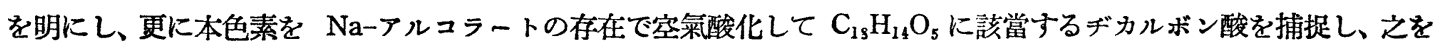
過マンガン酸加里て酸化して Fp $192^{\circ}$ のデカルボン酸 $\dot{\mathrm{C}}_{13} \mathrm{H}_{10} \mathrm{O}_{4}$ を得たが、之等の構造を明にするには到らなかつた。

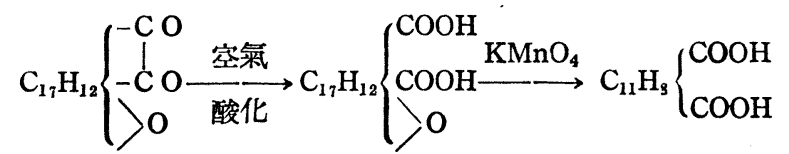

$$
\begin{aligned}
& \text { タンシノンI ヂフェン酸 Fp 192 の酸 }
\end{aligned}
$$

\footnotetext{
$\mathrm{COOH}$ 然るに最近に到つて Wessely 氏等2)は中星氏の得たる最終酸化成績體 $\left(\mathrm{Fp} 192^{\circ}\right)$ が1-メチ ルナフタリン $-5,6$ - デカルボン酸なることを明にし，更に本色素の構造を次のや5に推論し $\mathrm{COOH}$ てるる.

Wessely 氏によれば, タンシノン I にはメチル基が二箭存在し，クロム酸々化の際上記の メチルナフタリンヂカルボン酸と共に醋酸が生ずる故に, 一筬のメチル基は母核上に, 他の 一䉪は側鎖又は側環上に結合する. 又本色素は接觸還元の際まづ 1 モルの水素を急速に吸收
}

\footnotetext{
(1) 中尾, 福島: 本誌 54, 844 [昭 9].

(2) Wessely, Wang: Ber. 73, 19 [1940].
} 